\title{
Iatrogenic Venous Compression Syndrome due to Surgical Lumbar Hardware
}

\author{
Muhammad Akram Khan*, Zahoor Khan, Abeera Azam \\ Department of Cardiology, Cardiac Center of Texas, Baylor Heart Hospital, Plano, TX, USA.
}

\begin{abstract}
Background: The Iliac vein compression syndrome (IVCS) is most commonly due to May-Thurner variant, an anatomic variant where in the right common iliac artery overlies the left common iliac vein and compresses it against the lumbar spine. The compression of the common venous outflow tract of the left lower extremity may cause discomfort, swelling, or deep vein thrombosis in the iliofemoral veins. The role of the pelvic surgery particularly the lumbar hardware in the development of symptomatic Venous compression syndrome in patients with May-Thurner syndrome is not well understood. The incidence is presumably very low. Herein, we present six patients who developed IVCS after Lumbar hardware.

Method: The cases were diagnosed between Nov. 2016 to Oct. 2019 in the Outpatient Cath Lab of McKinney, TX. The patient's medical records were retrospectively analyzed looking for risk factors, clinical features, venogram findings, and post venogram. The evaluation of each case was described, and common trends were later presented in a cross-case analysis.

Conclusion: The cases presented in this report suggest that the hardware used in lumbar/spinal surgery could lead to an IVCS. Patient's symptoms are unspecific. Venogram/venoplasty is the gold standard for diagnosis and treatment. It is imperative having a high level of suspicion and familiarizing with the natural history of IVCS due to the invasive nature of venogram and the relevance of an early diagnosis to reduce the occurrences of complications.
\end{abstract}

Keywords: Venous disease, Iliac vein compression, May-Thurner syndrome, Lumbar surgery complications, Unexplained edema of left leg, May-Thurner Syndrome, Lumbar hardware, Venous compression, IVUS, Venogram, Angioplasty.

\section{INTRODUCTION}

The Iliac vein compression syndrome (IVCS) is most commonly due to May-Thurner variant, an anatomic variant where in the right common iliac artery (RCIA) overlies the left common iliac vein (LCIV) and compresses it against the lumbar spine $[1,2]$. The compression of the common venous outflow tract of the left lower extremity causes discomfort, swelling, or deep vein thrombosis in the iliofemoral veins. The prevalence of IVCS is approximately $20 \%$. Asymptomatic cases occur in $15-30 \%$ of the population [2]. Symptomatic patients typically present with acute or chronic edema of the lower limb, most often after surgery, pregnancy, travel, or prolonged immobility. The role of the pelvic surgery particularly the lumbar hardware in the development of symptomatic Venous compression syndrome in patients with May Thurner syndrome is not well understood. Iatrogenic causes of venous compression are rarely reported [3,4]. The incidence is presumably very low. Herein, we present six patients who developed IVCS after lumbar hardware.

\section{METHODS}

In a period between Nov. 2016 to Oct. 2019, six patients with history of surgical intervention of the lumbar spine were diagnosed with May-Thurner Syndrome in the Outpatient

*Address correspondence to this author at the Department of Cardiology, Cardiac Center of Texas, Baylor Heart Hospital, Plano, TX, USA.

Email: arhum2000@gmail.com
Cath Lab of McKinney, TX. The patient's medical records were retrospectively analyzed looking for risk factors, clinical features, venogram finding, and post venogram course in order to understand and describe the possible connections between the occurrence of the IVCS and the patient's risk factors. Each case was evaluated separately, and a cross case analysis was later performed to find common trends.

\section{MULTIPLE CASE REPORT}

Case 1 (c1). This patient was a 58-year-old female, obese, with past medical history (PMH) of hypertension (HTN), hyperlipidemia (HLD) and rheumatoid arthritis (RA) without history of deep venous thrombosis (DVT), coagulation disorders, use of oral contraceptive pills (OCP), or immobilizations. Because of her PMH of degenerative disc disease, she underwent spine surgery where lumbar hardware was used six months earlier. The initial physical examination (PE) showed bilateral lower extremities swelling, with predominance in the left leg.

Case 2 (c2). This 77-year-old female patient was a former smoker, with PMH of HTN, HLD, hypothyroidism, non-Hodgkin's lymphoma, abdominal aortic aneurysm, and peripheral vascular disease but without PMH of coagulation disorders, immobilization, or previous DVT. She underwent lumbar spinal surgery for her spinal stenosis with the use of hardware in March 2012. The subsequent exam showed intermittent 
swelling in both lower extremities.

Case 3 (c3). A 40-year-old female patient reported being a former smoker, without PMH of coagulation disorders, long term immobilization, OCP use, abortions, but with superficial phlebitis and previous DVT on the left leg, and peripheral neuropathy. Because of her $\mathrm{PMH}$ of spinal stenosis, she underwent a lumbar spinal surgery with hardware use in November 2012. Even though the initial patient physical exam showed no swelling on the lower extremities, she reported constant dull pain in the left lower leg.

Case 4 (c4). A 69-year-old female and obese patient reported being a former smoker, with PMH of coagulation disorders, factor VIII deficiency, with previous DVT and pulmonary embolism. Patient has history of HLD and coronary artery disease (CAD) for which she underwent heart bypass surgery in 1999. The patient denied OCP use, abortions, or long-term immobilizations. She had a lumbar spinal surgery with hardware use in 2012 due to her PMH of degenerative disc disease. The initial PE revealed swelling in both lower extremities accompanied by numbness and pain.

Case 5 (c5). This case is a 67-year-old male patient, obese, a former smoker with PMH of Diabetes mellitus, Hypertension, peripheral neuropathy, and degenerative disc disease. He did not have a history of immobilization but has protein $\mathrm{C}$ deficiency. This patient had one event of DVT and an inferior vena cava filter placement in 2010. In December 2016, he had a lumbar spinal surgery with hardware use. The subsequent physical examination revealed a remarkable swelling in the left leg accompanied by skin discoloration.

Case 6 (c6). This patient was a normal weight 68-year-old female with a PMH of Systemic Lupus Erythematous (SLE), HLD and thyroid disorders, without history of DVT, coagulation disorders, OCP, or immobilizations. Because of her PMH of degenerative disc disease, she underwent spine surgery on august and December 2018, where lumbar hardware was used. Immediately after the second surgery she had a DVT on the left lower extremity after the acute management for the vein thrombosis she came to our clinic for the post-thrombotic syndrome management. The patient was also complaining of recurrent left leg edema.

\section{CASE DIAGNOSIS AND MANAGEMENT}

To diagnose the cases a venogram was completed with intravascular ultrasound (IVUS) in each case. Left common iliac vein (LCIV) stenosis of $80 \%$ (c1), $90 \%(c 2), 99 \%(c 3)$, $50 \%$ (c4), $99 \%$ (c5), and $100 \%$ (c6) were confirmed (Appen$\boldsymbol{d i x} \boldsymbol{A})$. An iliac vein venoplasty and stenting was performed for case 1-5. For case 6, the revascularization was possible to cross the total occlusion but was not done due to the extensive presence of collateral circulation and a normal right iliac vein. The residual stenosis was considered 5, 20, 0, 20 and $100 \%$ (c1-6 correspondingly). After the procedure, the patients reported a significant improvement in symptoms and no recurrences have been registered in a period of $32,22,18,12$, 27 , and 2 months (c1-6 respectively).

\section{CROSS-CASE DISCUSSION}

IVCS is an underreported cause of DVT. May-Thurner syndrome is one of the most frequent causes of IVCS, and the most common scenario of the pathogenesis is LCIV at confluence crossed by RCIA which compress the vein against lumbar vertebras [1]. In the trapped vein, the intimal hypertrophy within the wall of the vessel causes endothelial changes and thrombus formation [2]. Many factors can contribute to the development of mechanical compression in susceptible individuals. Orthopedic surgery is a field commonly associated with complications like DVT formation or acute vascular damage; most of them venous injuries in nature [5-7]. However, there are only a few reports about Iatrogenic IVCS after lumbar surgery with hardware placement, which have similar findings in the multiple case report presented in this article [8-10].

The cross-case analysis presented here reports about six patients diagnosed with May-Thurner syndrome in the period between November 2016 to July 2018.

Findings are shown in Table $\mathbf{1 .}$ 


\section{APPENDIX A}

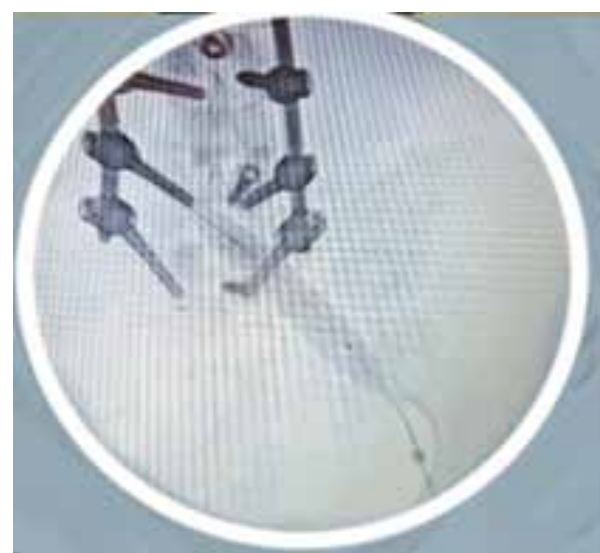

Fig. (1). Left Iliac Vein Compression, Shown is Balloon Dilatation Over the Wire. Stenting of the Vein with Post Stenting Stenosis of 5\%.

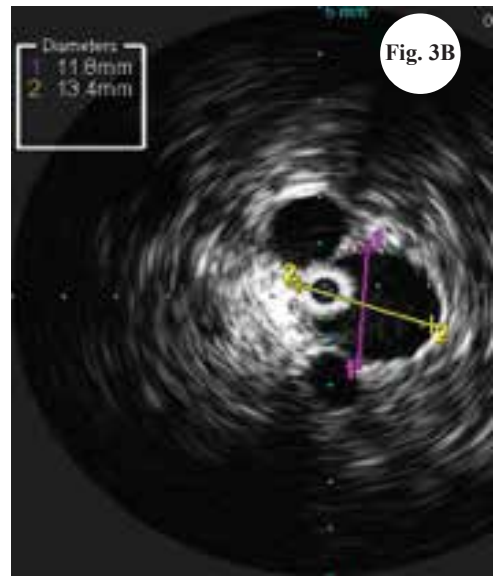

Fig. (3B). Demonstration of left iliac vein with luminal stenosis through IVUS.

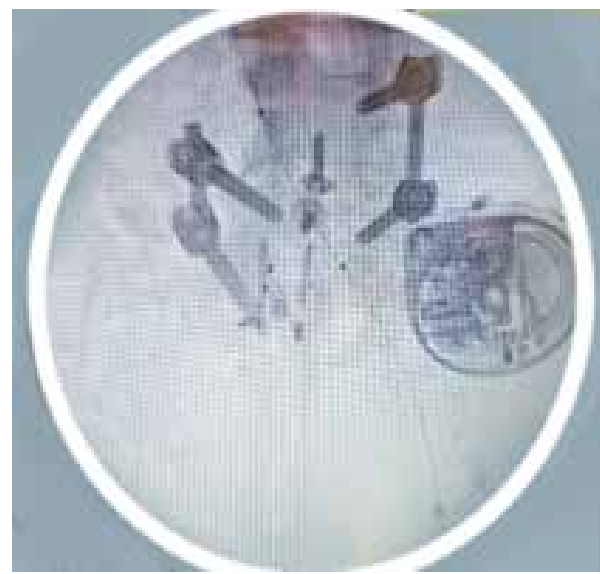

Fig. (5). Angiogram Findings of the Iliac Vein Stenosis.

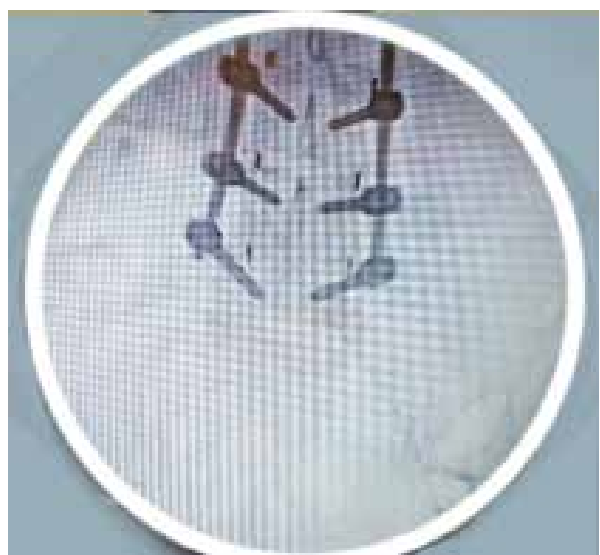

Fig. (2). Wire Shown in the Left Iliac Vein. Angiogram with Bilateral Stenosis with Subsequent Stent Placement.

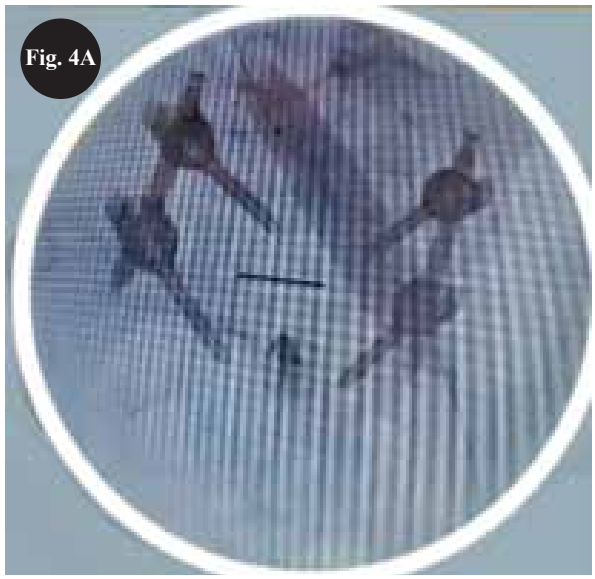

Fig. (4A). Right Iliac Vein Angiogram Finding of Dilation after Finding Stenosis.

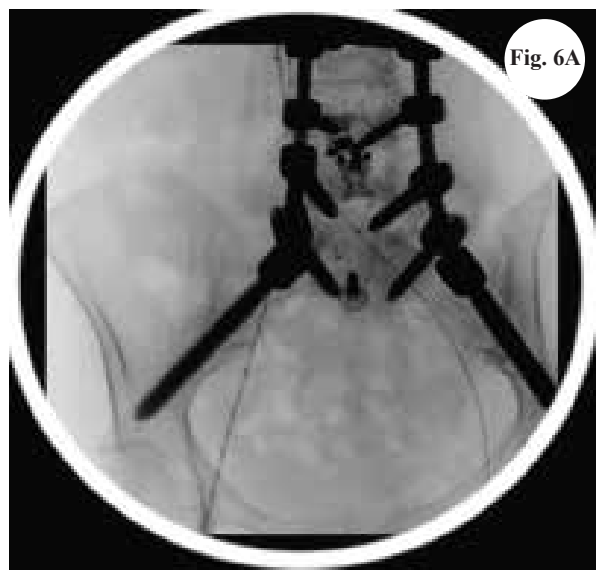

Fig. (6A). Angiogram Findings of the Left Vein Stenosis.

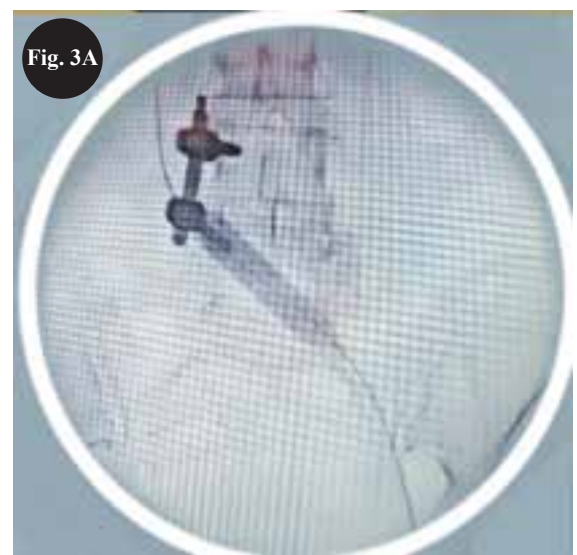

Fig. (3A). The Angiogram Findings of Left Iliac Vein Stenosis with Subsequent Balloon Dilatation and Stenting.

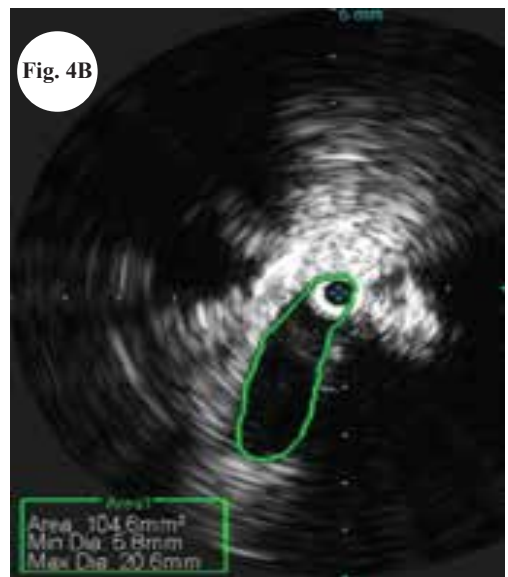

Fig. (4.B). IVUS Demonstration of the Stenosis of the Iliac Vein

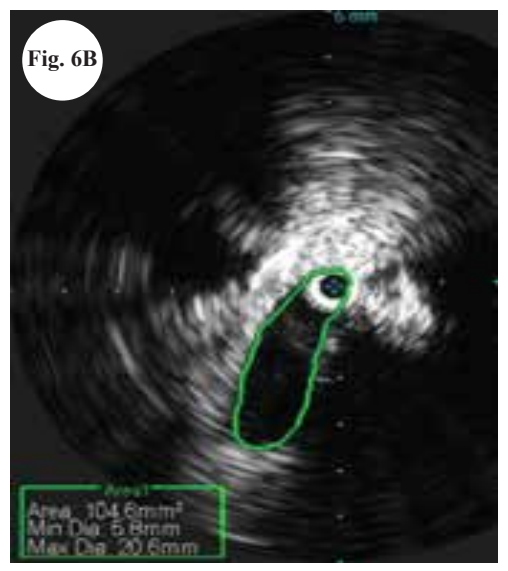

Fig. (6B). IVUS Finding of the Stenosis of the Left Iliac Vein. 
Table 1. IVCS Syndrome Patients' Comparison.

\begin{tabular}{|c|c|c|c|c|c|c|}
\hline Case & 1 & 2 & 3 & 4 & 5 & 6 \\
\hline Date of Venogram & $11 / 23 / 16$ & $9 / 13 / 17$ & $1 / 17 / 18$ & $7 / 14 / 18$ & $4 / 29 / 17$ & $10 / 9 / 19$ \\
\hline Sex & $\mathrm{F}$ & $\mathrm{F}$ & $\mathrm{F}$ & $\mathrm{F}$ & M & $\mathrm{F}$ \\
\hline Age & 58 & 77 & 40 & 69 & 67 & 68 \\
\hline $\begin{array}{c}\text { Initial PE } \\
\text { manifestations }\end{array}$ & $\begin{array}{l}\text { Swelling in legs } \\
\text { more in the left }\end{array}$ & $\begin{array}{c}\text { Bilateral intermittent } \\
\text { swelling in legs }\end{array}$ & Left lower leg pain & $\begin{array}{l}\text { Swelling, pain and } \\
\text { numbness on legs }\end{array}$ & $\begin{array}{l}\text { Swelling left leg and } \\
\text { skin discoloration }\end{array}$ & $\begin{array}{l}\text { Left lower leg } \\
\text { swelling, } \\
\text { post-thrombotic } \\
\text { syndrome }\end{array}$ \\
\hline Past medical history & $\begin{array}{l}\text { DM, HTN, HLD, } \\
\text { RA. }\end{array}$ & $\begin{array}{c}\text { HTN, HLD, } \\
\text { hypothyroidism } \\
\text { non-Hodgkin's } \\
\text { lymphoma, mild } \\
\text { mitral regurgitation, } \\
\text { AAA, PVD. }\end{array}$ & $\begin{array}{c}\text { Peripheral } \\
\text { neuropathy, } \\
\text { superficial phlebitis, } \\
\text { DVT left leg }\end{array}$ & $\begin{array}{c}\text { Iatrogenic DVT, } \\
\text { pulmonary } \\
\text { embolism, factor } \\
\text { VIII deficiency } \\
\text { HLD, CAD }\end{array}$ & $\begin{array}{c}\text { DM, HTN, } \\
\text { peripheral } \\
\text { neuropathy, DVT, } \\
\text { protein C deficiency }\end{array}$ & $\begin{array}{c}\text { DVT, SLE, thyroid } \\
\text { disorders, HLD }\end{array}$ \\
\hline Past surgical history & $\begin{array}{c}\text { Lumbar spine fusion } \\
\text { (hardware) }\end{array}$ & $\begin{array}{c}\text { Lumbar spine fusion } \\
\text { (hardware) }\end{array}$ & $\begin{array}{l}\text { Lumbar spine fusion } \\
\text { (hardware) }\end{array}$ & $\begin{array}{c}\text { Heart bypass, } \\
\text { Lumbar spine fusion } \\
\text { (hardware) }\end{array}$ & $\begin{array}{c}\text { IVC filter, neck } \\
\text { surgery } \\
\text { Lumbar spine fusion }\end{array}$ & $\begin{array}{c}\text { Lumbar spine fusion } \\
\text { (hardware) }\end{array}$ \\
\hline $\begin{array}{c}\text { Reason for back } \\
\text { surgery }\end{array}$ & $\begin{array}{c}\text { Degenerative disc } \\
\text { disease }\end{array}$ & $\begin{array}{c}\text { Lumbar spinal } \\
\text { Stenosis }\end{array}$ & $\begin{array}{c}\text { Lumbar spinal } \\
\text { stenosis }\end{array}$ & $\begin{array}{c}\text { Degenerative disc } \\
\text { disease }\end{array}$ & $\begin{array}{c}\text { (hardware) } \\
\text { Degenerative disc } \\
\text { disease. Cervical and }\end{array}$ & $\begin{array}{c}\text { Degenerative disc } \\
\text { disease }\end{array}$ \\
\hline Date of back surgery & $6 / 2016$ & $3 / 2012$ & $11 / 2011$ & 2012 & $\begin{array}{l}\text { lumbar disc prolapse } \\
\qquad 12 / 2016\end{array}$ & $08 / 2018$ and $12 / 2018$ \\
\hline \multicolumn{7}{|c|}{ Other Risk Factors of DVT } \\
\hline Immobilization & No & No & No & No & No & No \\
\hline OCPs use. & No & No & No & No & Not applicable & No \\
\hline Obesity & Overweight & Normal Weight & Normal weight & Obese & Obese & Normal Weight \\
\hline $\begin{array}{l}\text { Familial hyper } \\
\text { coagulopathy }\end{array}$ & No & No & No & No & No & No \\
\hline $\begin{array}{l}\text { First trimester } \\
\text { abortion }\end{array}$ & No & No & No & No & Not applicable & No \\
\hline \multicolumn{7}{|l|}{ Travel Habits } \\
\hline Smoking & No & Yes & Yes & Yes & Yes & No \\
\hline Alcohol abuse & No & No & No & No & No & Yes \\
\hline Recreational drugs & No & No & No & No & No & No \\
\hline Regular exercise & No & No & No & No & No & Yes \\
\hline $\begin{array}{l}\text { Findings on } \\
\text { venogram }\end{array}$ & $\begin{array}{c}80 \% \\
\text { stenosis }\end{array}$ & $\begin{array}{c}90 \% \\
\text { Stenosis }\end{array}$ & $\begin{array}{c}99 \% \\
\text { stenosis }\end{array}$ & $\begin{array}{l}>50 \% \\
\text { stenosis }\end{array}$ & $\begin{array}{c}99 \% \\
\text { stenosis }\end{array}$ & $\begin{array}{c}100 \% \\
\text { stenosis }\end{array}$ \\
\hline Stenting performed & Yes & Yes & Yes & Yes & Yes & No \\
\hline Residual stenosis & $<5 \%$ & $20 \%$ & $0 \%$ & $20 \%$ & $30 \%$ & $100 \%$ \\
\hline
\end{tabular}


The six cases presented in this report had a history of lumbar spinal fusion which was surgically treated with lumbar hardware. Two out of six patients had surgery due to spinal stenosis, three had surgery due to degenerative disc disease, and one of them had surgery due to cervical and lumbar disc prolapse. Five patients presented leg swelling and pain, with predominance in the left leg, in an elapse of six months to several years after spinal surgery but one patient suffered an acute DVT in the first 24 hours after lumbar surgery. None of them reported OCP use, first-trimester abortion, or recent travel. Three of the patients had documented hypercoagulability, patient 5 has protein $\mathrm{C}$ deficiency, patient 4 had history of DVT, pulmonary embolism with infarction, and patient 6 had SLE. Also, Patient 3 had history of three previous DVT on the distal left leg and superficial phlebitis. Case 1 and 5 are Diabetics and obesity or overweight was evident in three of them. Four patients had a history of heavy smoking. The labs performed showed unremarkable results at the time when the IVCS was diagnosed. Iliac vein ultrasound scan done on all the patient showed positive deep vein reflux followed by venogram/venoplasty. Acute DVT was ruled out in all patients.

Endovascular treatment, such as percutaneous angioplasty with stent placement is favored, and it has been used since 1995 [11]. Treatment depends on the severity and location of the vein compression. However, venogram and IVUS for diagnosis and therapeutic venoplasty with or without stenting have become the first choice for diagnosis and post stenting confirmation. In addition to IVUS being the gold standard for diagnosis it is currently the most used procedure to determine the severity of stenosis. For this reason, venogram and IVUS were used in all the cases reported above and venoplasty with stenting was done in five of them. All the patients reported significant improvement in symptoms after these procedures. No recurrences of the IVCS have been observed in the patients presented in this report.

\section{CONCLUSION}

The cases presented in this report suggest that the hardware used in lumbar/spinal surgery could lead to an iatrogenic compression of the left common iliac Vein. The natural evolution of the scaring process and the proximity between vascular structures in the pelvic region with the hardware placed in the lumbar spine surgery could produce a disturbance of the normal pelvic vascular anatomy and favor the compression of the iliac vein. This anatomic disturbance combined with a hypercoagulable state such as SLE, protein C deficiency, DM or surgery could promote the occurrence of an early symptomatic May-Thurner syndrome. Therefore, it is crucial to recognize the history of lumbar surgery with hardware as a potential contributing or causal factor in those patients who present with pain or swelling in the lower extremities or DVT. The presentation of IVCS after lumbar surgery could be unspecific, and event simulates other more common pathologies. Standard imaging techniques are not always reliable to detect the interference of orthopedic hardware with essential internal structures. Our six patients were diagnosed by venogram and IVUS, which is the gold standard not only due to its high sensitivity and specificity for this entity but because it can be therapeutic through angioplasty and stenting. The angioplasty with or without stenting placed has achieved a low recurrence rate [8-11]. It is imperative having a high level of suspicion and familiarizing ourselves with the natural history of IVCS due to the invasive nature of venogram and the relevance of an early diagnosis to reduce the occurrences of complications of this not so rare disease that can lead to severe DVT, Pulmonary embolism or an uncomfortable and persistent discomfort in our patients.

\section{AUTHORS' CONTRIBUTION}

All authors have contributed equally.

\section{CONFLICT OF INTEREST}

Declared none.

\section{ACKNOWLEDGEMENTS}

Declared none.

\section{REFERENCES}

[1] Mousa AY, AbuRahma AF. May - Thurner syndrome: Update and review. Ann Vasc Surg 2013; 27(7): 984-95.

DOI: 10.1016/j.avsg.2013.05.001

[2] May R, Thurner J. The cause of the predominantly sinistral occurrence of thrombosis of the pelvic veins. Angiology 1957; 8(5): 419-27. DOI: $10.1177 / 000331975700800505$

[3] McAree BJ, O'Donnell ME, Fitzmaurice GJ, Reid JA, Spence RAJ, Lee B. Inferior vena cava thrombosis: A review of current practice. Vasc Med 2013; 18(1): 32-43.

DOI: $10.1177 / 1358863 X 12471967$

[4] Mody BS. Pseudoaneurysm of external iliac artery and compression of external iliac vein after total hip arthroplasty. Case report. J Arthroplasty 1994; 9(1): 95-8.

DOI: 10.1016/0883-5403(94)90143-0

[5] Reddy D, Mikhael MM, Shapiro GS, Farrell T. Extensive deep venous thrombosis resulting from anterior lumbar spine surgery in a patient with iliac vein compression syndrome: A case report and literature review. Global Spine J 2015; 5(4): e22-7. DOI: 10.1055/s-0034-1396431

[6] Dandachli W, Cobb JP. Complications in orthopaedic surgery. In: Hakim N, Vassilios E, Eds. Papalois Surgical Complications: Diagnosis and Treatment. London: Imperial College Press 2007; pp. 689-725. DOI: 10.1142/9781860948329_0021

[7] Garg J, Woo K, Hirsch J, Bruffey JD, Dilley RB. Vascular complications of exposure for anterior lumbar interbody fusion. J Vasc Surg 2010; 51(4): 946-50.

DOI: $10.1016 /$ j.jvs.2009.11.039

[8] Mathur M, Shafi I, Alkhouli M, Bashir R. Surgical hardware-related iatrogenic venous compression syndrome. Vasc Med 2015; 2020; 20(2):162-7.

DOI: $10.1177 / 1358863 X 14559093$ 
[9] Woo EJ, Ogilvie RA, Krueger VS, Lundin M, Williams DM. Iliac vein compression syndrome from anterior perforation of a pedicle screw. J Surg Case Rep 2016; 2016(2): rjw003 DOI: $10.1093 /$ jscr/rjw003

[10] Berger A, Jaffe JW, York TN. Iliac compression syndrome treated with stent placement. J Vasc Surg [Internet]. 1995; 21(3): 510-4. DOI: 10.1016/S0741-5214(95)70295-4

[11] Kapto AA. Arteryovenous conflicts in men with urological pathology. Urol Rep 2018; 8(2): 53-63.

DOI: $10.17816 /$ uroved8253-63

(C) 2020 National Journal of Health Sciences.

This is an open-access article. 